
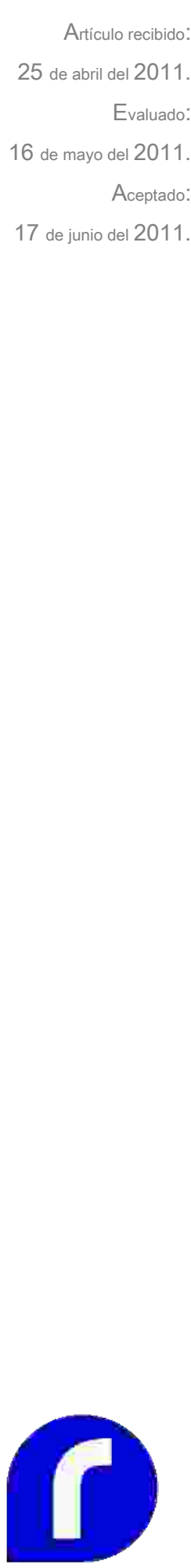

Luis Paulino Vargas Solís

\section{Costa Rica: Tercera fase de la estrategia neoliberal. Contradicciones y desafíos (2005-2010)}

R ESUMEN

Con la instalación de Intel en 1998 la estrategia neoliberal en Costa Rica entró en una nueva etapa que superaba a la de "exportación ligera" del período 1985-1997, para dar paso a las exportaciones originadas en corporaciones transnacionales de alta tecnología, a lo cual se unía la instalación de cadenas hoteleras transnacionales. En 2005 la estrategia pasa a una tercera etapa, en la cual los flujos de capitales -en particular los capitales de corto plazose vuelven tan significativos que no solo se convierten en la fuerza principal que determina la evolución de la economía, sino que también tiene un impacto tal en el tipo de cambio real colón-dólar, que introducen contradicciones inéditas que, a su vez, subvierten la base exportadora en que la estrategia se sustenta. Así, la incorporación irrestricta de Costa Rica en la globalización financiera, adquiere un matiz conflictivo que amenaza desmembrar el tejido exportador y turístico que ha sustentado la economía, como también hace aparecer nuevos elementos de inestabilidad.

PALABRAS CLAVE

Neoliberalismo, política cambiaria, modelo neoliberal, globalización, capital especulativo, crisis económica, competitividad.

\section{Costa Rica: Third stage of neoliberal strategy. Contradictions and challenges (2005-2010)}

A BSTRACT

When Intel started its production process in Costa Rica in 1998, at the same time the neoliberal strategy entered in a new phase. From 1985 to 1997 it was the "light exportation phase". After 1998 it was the time for high technology corporations and transnational hotel chains to take a part of that scenario. However, in 2005 a third phase started, a phase that was characterized by the dominance of capital flows, mostly short term capitals. That capital did not just only lead the evolution of the economy, but also provoked the real value of the rate colon-dollar to rise consistently trough the period that started in 2005. All of this brought new contradictions, unknown for the neoliberal strategy, mostly because it implied to harm the economical structure based on exportation and tourist activities. Moreover, it suggested that Costa Rica had fully entered in financial globalization, and this implied a very serious risk in terms of both, the damage to that economical structure, and the point of view of the instability that it carried.

\section{KEY WORDS}

Neoliberalism, exchange policy, neoliberal model, globalization, speculative capital, economic crisis, competitiveness.

Economista y Máster en relaciones internacionales. Doctor en gobierno y políticas públicas. Catedrático Universitario. Actualmente es Director a.i. del Centro de Investigación en Cultura y Desarrollo (CICDE) de la Vicerrectoría de Investigación de la Universidad Estatal a Distancia (UNED). Ganador del Premio Nacional Aquileo Echeverría 2011 por su libro "La llave y el candado. Realidad e ideología de la propiedad intelectual" (Editorial UNED, 2010). Correo electrónico: Ipvaso@gmail.com 


\section{Costa Rica: Tercera fase de la estrategia neoliberal. Contradicciones y desafíos (2005- 2010)}

\section{Introducción}

El principal sostén de la economía de Costa Rica durante el primer decenio del siglo XXI, especialmente durante el segundo lustro de ese decenio, ha sido, fundamentalmente, la atracción de inversión extranjera directa. Esto no es novedoso si se toma en cuenta la situación de pertinaz déficit en la cuenta corriente que, en el muy largo plazo, vive la economía de Costa Rica. Tampoco hay en ello nada peculiar desde el punto de vista de que, en general, las propuestas de reestructuración económica neoliberal ya proponían, incluso desde los años ochenta del siglo pasado, que el capital extranjero habría de ser un elemento importante dentro de esa estrategia. Sin embargo, y como se demostrará en este artículo, en el período reciente los flujos de capital $-y$ en particular los capitales de corto plazo, más que la inversión directaasumen un rol fundamental, al punto que ello da lugar a una nueva etapa en el devenir del modelo o estrategia neoliberal. Esa nueva etapa empieza en 2005 y constituye una tercera fase en la evolución de ese modelo desde su implantación original, a mediados del decenio de los ochenta en Costa Rica. Sin embargo, y excepto que se logre introducir a tiempo los correctivos que son necesarios, esta tercera etapa comportaría la subversión del modelo neoliberal en relación con los que, hasta la fecha, han sido sus pilares fundamentales: el crecimiento de las exportaciones y el turismo. 


\section{Bases teórico-ideológicas de la estrategia neoliberal}

En general, la literatura económica que formalizó y racionalizó la propuesta neoliberal enfatizaba claramente ciertos asuntos. En particular se proponía avanzar en un proceso de reestructuración que, a un mismo tiempo, debía redefinir una serie de aspectos sustantivos (Lizano, 1988, 1999, 2010; ver también Lizano y Zúñiga, 1999):

- El papel del Estado y las políticas públicas frente al peso e influencia de los mecanismos del llamado libre mercado;

- Las características y funcionamiento del sistema bancario y, en particular, de la banca pública relativamente a la privada;

- El papel del mercado nacional y centroamericano correlativamente a los "terceros mercados". Este último concepto esencialmente hacía referencia al mercado estadounidense $\mathrm{y}$, secundariamente, al europeo;

- Los parámetros de funcionamiento del sistema de precios y, en particular, la liberalización y desregulación de los mercados;

- La naturaleza y profundidad de los nexos con el mercado capitalista mundial, especialmente en relación con la apertura indiscriminada y unilateral a las importaciones y al capital extranjero.

La propuesta estaba formulada a partir del diagnóstico generado en relación con la crisis de 1980-1982, el cual enfatizaba factores asociados principalmente con el crecimiento del Estado, considerado excesivo, y, correlativamente, las formas de intervención pública en los mercados, que se estimaban eran distorsionantes. El crecimiento, presuntamente desordenado, del gasto público condujo a un excesivo, y finalmente insostenible, endeudamiento público, en tanto que la intervención en los mecanismos del mercado generó una estructura productiva ineficiente. En particular, el elevado proteccionismo que favorecía tanto a la industria (mediante elevados aranceles) y la agricultura (precios de sustentación, compra de excedentes, crédito subsidiado, restricción a las importaciones), hacía depender el crecimiento económico del mercado nacional $y$, a lo sumo, el centroamericano, los cuales, siendo relativamente pequeños, ponían un techo a las posibilidades de crecimiento. Se entiende, pues, que la combinación entre un sector público en rápida expansión y una economía ineficiente habría finalmente conducido a una situación insostenible, lo cual se puso de manifiesto en el elevado nivel del endeudamiento público externo, el cual llevó al país a una situación de insolvencia que lo precipitó en una prolongada y severa crisis económica, cuyas primeras manifestaciones datan de 1979, y la cual alcanza una fase de severa recesión con elevada inflación hacia 1981-1982. 
El diagnóstico así formulado no tomaba en cuenta que, sin embargo, el problema del endeudamiento público había alcanzado niveles críticos en prácticamente toda América Latina. Al enfatizar el presunto descontrol en el gasto público, que habría propiciado los excesos de la deuda, se olvidaba señalar que ese era un proceso del que también era partícipe y responsable la banca transnacional, que activamente lo promovió. Finalmente ese diagnóstico tampoco consideraba que la crisis de la deuda latinoamericana explotó en un contexto internacional sumamente adverso, el cual incluía el aumento -a niveles excepcionalmente elevados- de las tasas de interés internacionales, como resultado de la aplicación de una política monetaria altamente restrictiva por parte de la Reserva Federal de Estados Unidos, cuyo objetivo era reducir drásticamente los niveles de inflación ${ }^{1}$. Esto estuvo antecedido por el segundo gran aumento del petróleo promovido por la Organización de Países Exportadores de Petróleo (OPEP) a finales de los setentas y coincidió con una de las recesiones más largas y agudas registradas en Estados Unidos durante el período posterior a la Segunda Guerra Mundial, con excepción de la Gran Recesión de 2008-2009².

Eludir en el análisis estas problemáticas facilitaba encubrir la orientación ideológica que guiaba las propuestas formuladas. Estas se encaminaban hacia una reestructuración de la economía costarricense que partía de un fuerte anti-estatismo y se dirigieron hacia la exaltación apologética de los así llamados libres mercados, con prescindencia de cualquier consideración más amplia, atinente a los antecedentes históricos del desarrollo de la economía costarricense, como también se obviaban las evoluciones y tendencias de la economía mundial y los impactos que todo ello tenía sobre la costarricense.

Puesto que el diagnóstico se formulaba a partir de la crítica esencialmente ideológica- al papel y al tamaño del Estado, y a las formas y alcance de la intervención de este último en los mecanismos del mercado. De ahí derivaba -al menos en el nivel discursivo- hacia la tonalidad esperable: el énfasis en la liberalización de la economía. Ello incluía diversos frentes sobre los cuales debía actuarse: desgravación arancelaria, desregulación de mercados, desregulación financiera, impulso al crecimiento de la banca privada. Posteriormente Lizano (2000) conceptuaría esta estrategia como el modelo de liberalización económica (LE) que ese autor contraponía con el modelo gremialismo-populismopaternalismo (GPP). A juicio de Lizano este último correspondía a la estrategia económica vigente durante el período previo a la crisis de inicios de los años ochenta del siglo XX, en particular los decenios de los sesentas y setentas. De tal forma, el planteamiento de este autor -que luego fue asumido por otros economistas de similar filiación ideológica y ampliamente difundido por los medios de prensa- sugiere dos opciones polares y contrapuestas, que son, asimismo, las únicas dos posibles. Vale decir, no admite otras alternativas como no sean esas dos.
1. Al respecto, dice Greenspan (2008, p. 102): "Las consecuencias de su política [la de Paul Volcker como Presidente de la Reserva Federal de Estados Unidos] fueron más severas incluso de lo que Volcker había esperado. En abril de 1980 los tipos de interés de Estados Unidos subieron hasta superar el 20 por ciento". Para el caso centroamericano, esta situación fue en su momento estudiada por López (1986) y Timossi (1989).

2. De acuerdo con el National Boureau of Economic Research de Estados Unidos, la recesión de 19811982 se extendió por 16 meses e implicó una baja del $-2,7 \%$ en la producción desde su máximo previo y un pico de desempleo abierto del 10,8\%. En términos de duración igualó a la de 1974-1975, pero esta trajo una reducción del $-3,2 \%$ en la producción si bien con un desempleo no tan elevado $(9,0 \%)$. Un agravante en relación con la recesión de 1981-1982 es que esta estuvo antecedida -con apenas 1 año y cuatro meses de diferencia- por una corta recesión (seis meses) durante el primer semestre de 1980. Las de 1974-1975 y 1981-1982 son consideradas las dos recesiones más importantes en Estados Unidos, durante el período posterior a la Segunda Guerra Mundial, con excepción de la Gran Recesión de 2008-2009 (disponible en http://www.nber.org/). 
3. Al respecto, indica Stiglitz (2006, p. 59): “La globalización -en forma de crecimiento basado en las exportaciones- contribuyó a sacar a los países del Este asiático de la pobreza (...) Pero estos países gestionaron la globalización: fue su capacidad para sacar partido de la misma, sin que esta se aprovechara de ellos, lo que explica su éxito". Véase también López (1999). En general, la intervención del Estado como modulador del mercado para la creación de condiciones propicias al desarrollo capitalista está presente en la mayoría sino la totalidad de las experiencias capitalistas exitosas (Chomsky, 1995). En todo caso, y frente a las versiones más optimistas con las que se ven tales procesos como un "destino feliz" más o menos al alcance de cualquier país subdesarrollado que así se lo proponga (por ejemplo Villamizar y Mondragón, 1995; ver también Sachs, 2006; Shenkar, 2008), aparecen las versiones críticas que profundizan en el carácter desequilibrado y desigual de los procesos de desarrollo del capitalismo, particularmente durante la actual fase de globalización neoliberal (Vilas, 2003; Amín, 1999, 2005).
Se trata, pues, de un enfoque excesivamente simplificado e, incluso, maniqueísta, según el cual toda posibilidad de avance y progreso está inexorablemente vinculada al modelo LE, y cualquier otra alternativa es reaccionaria porque invariablemente conduce de vuelta hacia el pasado, en la forma del modelo GPP. Es una formulación que ignora notables experiencias históricas de desarrollo como las del sudeste asiático, que han implicado acelerados procesos de modernización capitalista y reducción de la pobreza, los cuales usualmente se han basado en altos niveles de intervención estatal y movimientos, muy estudiados y graduales de apertura a los mercados mundiales ${ }^{3}$. Como instrumento de propaganda, formulado con fines evidentemente políticos, demostró ser una táctica poco sutil pero relativamente eficaz. Como propuesta académica e intelectual es, en el mejor de los casos, una hipótesis insatisfactoria por simplista y deshistorizada.

\section{La estrategia neoliberal en Costa Rica}

En la práctica, y no obstante la atribución que se hace en términos de una estrategia o "modelo" de liberalización (LE en la conceptuación de Lizano), en realidad, en su concreta configuración histórica, esa estrategia incorpora importantes componentes proteccionistas y de promoción activa por parte del Estado. Ello es muy claro respecto de las llamadas exportaciones no tradicionales (así llamadas a mediados de los ochenta del siglo XX, cuando se puso en marcha el generoso aparato de fomento exportador) y el turismo. Pero ello es cierto incluso respecto de la banca privada, activamente promovida, al menos durante los ochenta, por medio de recursos públicos, gran parte de los cuales provenían del gobierno estadounidense y venían condicionados a que fuesen destinados a las llamadas exportaciones no tradicionales mediante su canalización vía banca privada (Sojo, 1991, 1992). De tal forma, el impulso al negocio financiero privado tiene lugar de forma simultánea y concomitante, con la aplicación de una agresiva política de fomento a las exportaciones y al turismo la cual implicó un elevado costo fiscal y recibió un empujón muy vigoroso a partir de 1984 (Vargas, 2002).

Se podría considerar paradójico que una propuesta que en el nivel discursivo se plantea como de liberalización de mercados, se concrete, sin embargo, como una política de fomento deliberado de ciertas actividades económicas, en función de lo cual se incurre, incluso, en elevados costos fiscales. La duda queda despejada en cuanto se advierte que, en realidad, esta estrategia refleja determinadas correlaciones de poder, cuya justificación se ve favorecida por un discurso que hace apología del mercado, y que, en cuanto tal, actúa como cubierta legitimadora de un nuevo aparato de proteccionismo estatal, en este caso sesgado a favor de reducidos grupos de interés económico (Vargas, 2010). 
En adelante, esta estrategia de desarrollo económico será identificada como estrategia neoliberal, por referencia a la ideología que la informa y legitima. Como se muestra en otros trabajos (Vargas 2008a; 2008b; ver también Villarreal, 1984) el neoliberalismo es la ideología que marca y significa al actual período histórico de desarrollo del capitalismo mundial. Por lo tanto aparece vinculada, como discurso de legitimación, con la expansión planetaria del capital transnacional visibilizado en las corporaciones transnacionales $y$, en particular, con el despliegue de la globalización financiera y el desarrollo de un gigantesco aparato planetario de especulación que integra en tiempo real todas las plazas financieras importantes a escala planetaria (Plihon, 2003; Sevares, 2005; Soros, 2008; Stiglitz, 2006, 2010). El neoliberalismo aparece discursivamente como una ideología del libre mercado. En la práctica, y en uno de sus aspectos, tiende a ser una ideología imperialista que legitima la expansión planetaria del capital transnacional y los procesos de repartición de mercados (Petras y Veltmeyer, 2004; Amín, 1999, 2005). En algunas de sus variantes, actúa como artilugio que encubre prácticas comerciales proteccionistas, discriminantes y hasta depredadoras, por parte de los países avanzados del capitalismo mundial respecto de los más pobres (Stiglitz, 2006).

Esta estrategia de liberalización ha modificado de forma muy considerable el paisaje económico y social de Costa Rica. Sus éxitos principales se visibilizan en el importante aumento y diversificación de las exportaciones, así como en el notable crecimiento del turismo, lo cual ha estado acompañado de un estancamiento en los niveles de pobreza (en los alrededores del $20 \%$ del total de familias y $24 \%$ de la población) y un incremento importante en los niveles de desigualdad (el coeficiente de Gini se situaba a finales de los ochenta en valores de 0,37-0,38. Un decenio después superó el valor de 0,40 mientras en los últimos años alcanza niveles de alrededor de 0,44). En el período reciente -2005 hasta el momento actual- la afluencia de capital extranjero se incrementa de forma extraordinaria $y$, como se verá más adelante, provoca una redefinición de fondo en las orientaciones centrales de la estrategia de liberalización. Este artículo intenta demostrar esta última tesis para, a partir de ahí, clarificar que esto comporta un predicamento de compleja resolución, en virtud del cual se pone en cuestión el conjunto de la estrategia vigente.

\section{Evolución y ciclicidad de la economía costarricense: las tres fases en el devenir de la estrategia neoliberal}

En Loría (2005) y Lizano (2005) ya se admitía que el peso adquirido por la inversión extranjera en Costa Rica podría significar un factor que, eventualmente, incidiría en el grado de volatilidad y vulnerabilidad de la economía costarricense. Sin embargo, y como conclusión general, estos 
autores coincidían en enfatizar que la economía costarricense habría vivido un largo período (1984-2004) "sin nuevas crisis". Ello muy claramente sugiere que la estrategia neoliberal habría creado condiciones de relativa estabilidad económica.

Sin embargo, basta un examen superficial de los datos disponibles para poner en claro un patrón bien definido y mucho menos halagador de lo que, a primera vista, sugiere esa conclusión, en la forma, particularmente, de una marcada ciclicidad económica, la cual es característica de este período (Vargas, 2003): fases muy breves de relativo alto crecimiento (1992-1993; 1998-1999) precedidas o seguidas de otros de muy inferior crecimiento (1990-1991; 1995-1996; 2000-2002) (Gráfico 1). Hasta desembocar en la situación registrada en el último lustro, donde una expansión de naturaleza especulativa -por ello mismo insostenible- en los años 2006-2007 (Vargas, 2008c) cede lugar a un ciclo de bajo crecimiento a partir de 2008, el cual se convierte en recesión en 2009. Es claro que este último y pronunciado bajón, ha estado vinculado a la crisis económica mundial. Sin embargo, no es posible pasar por alto que ha existido un patrón estructural subyacente, que ha marcado el devenir de la economía costarricense con el signo de una pronunciada ciclicidad, la cual se hace manifiesta no solo en el comportamiento del PIB, sino también en la evolución de los precios y del déficit fiscal (Gráfico 2). En tal caso, el bajón de 2009 habría sido una nueva manifestación de ese patrón, solo que agudizada a raíz de la Gran Recesión mundial de 2008-2009. Esta última, sin embargo, es una observación que exige algunas precisiones y matizaciones, como en seguida se verá.

En general, ese patrón cíclico parece ser el resultado combinado de diversos factores, cuyo peso relativo tiende a modificarse a lo largo del tiempo. Es en función de la relevancia que esos factores adquieren en los distintos momentos, que aquí se diferencian tres distintas fases en el devenir de la estrategia neoliberal.

La primera fue la fase de exportación ligera (maquila textil, nuevos productos de exportaciones agrícolas y del mar, industria tradicional, turismo todavía con un componente dominante de capital nacional), la cual inicia en 1984, cuando toma forma el aparato de promoción de las exportaciones y el turismo, y se extiende hasta 1997 (Vargas, 2002). Conviene resaltar que esta política se sustentaba en un aparato de estímulo principalmente fiscal, mediante exenciones tributarias.

La segunda fase inicia en 1998, con la implantación en Costa Rica de la transnacional Intel, lo cual promueve, a su vez, la llegada de otras compañías trasnacionales de alta tecnología, incluyendo tecnologías de la información, farmacéutica y tecnologías médicas, entre otras. Se trata de empresas que se acogen a los beneficios tributarios existentes pero que reciben otros apoyos por parte del gobierno de turno (en relación, por ejemplo, con los trámites aduanales o incluso, como en el caso de Intel, 


\section{Gráfico 1}

Costa Rica: déficit del sector público global (\% del PIB) y variación anual del Producto Interno Bruto (PIB)

Cifras porcentuales

1984-2010

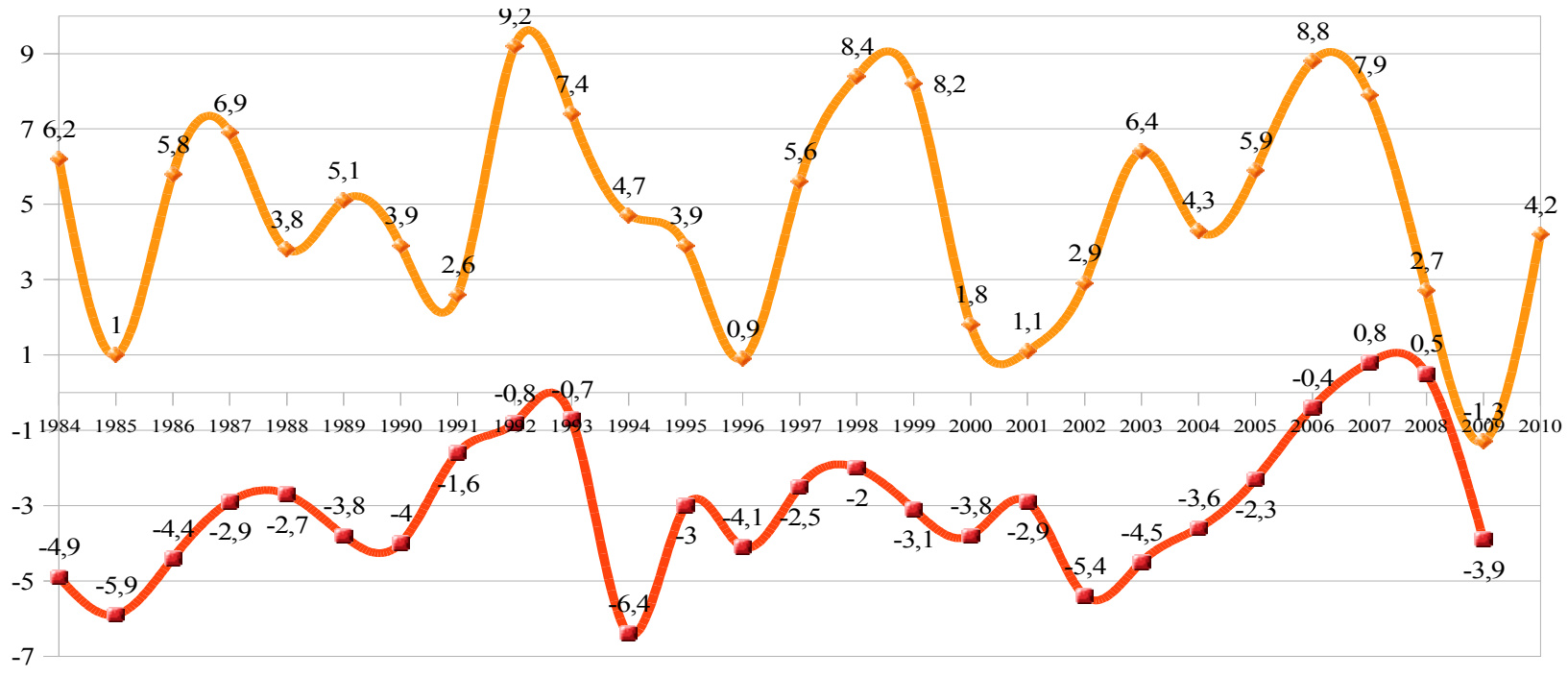

$\rightarrow$ PIB-\%variación anual - Déficit global sector públic

Fuente: elaboración propia con base en datos del Banco Central de Costa Rica

Gráfico 2

Inflación medida según variación anual del Índice de Precios al Consumidor (IPC)

1984-2010

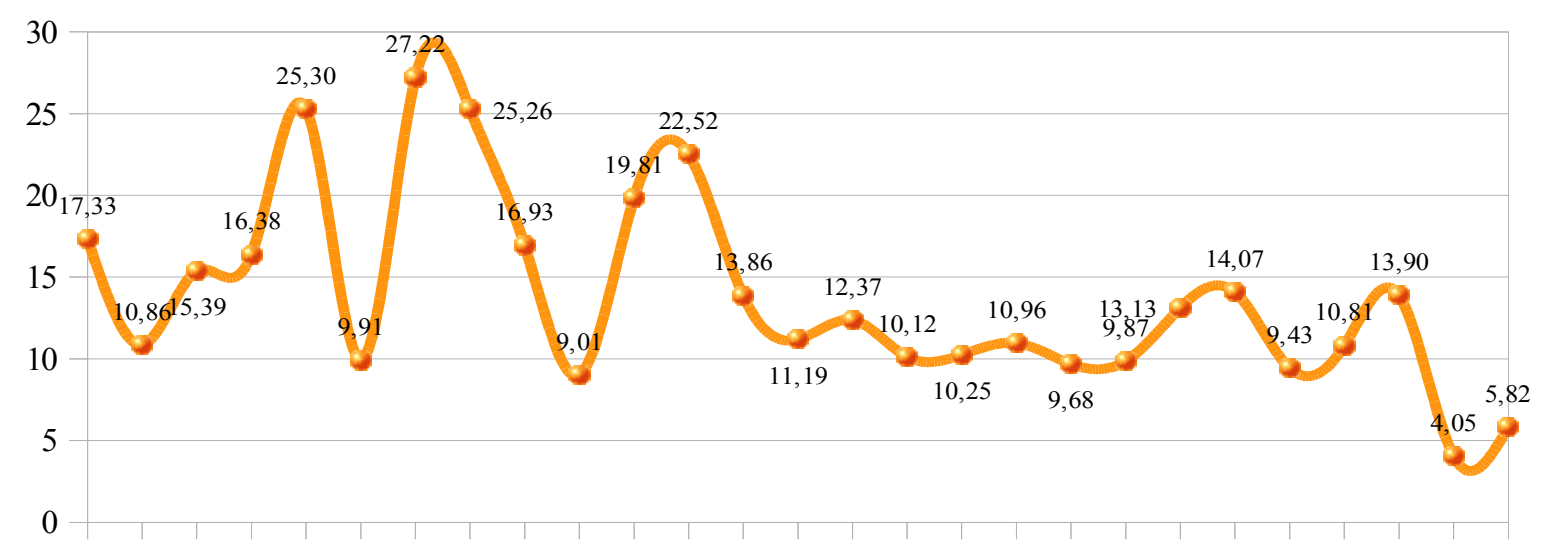

- IPC-variación anual \%

Fuente: Elaboración propia con base en datos del Instituto Nacional de Estadísticas y Censos (INEC) 
tarifas eléctricas diferenciadas), y las cuales se instalan en zona franca. El peso que estas empresas adquieren se refleja muy claramente en la importancia relativa que, dentro del total de las exportaciones, adquieren aquellas que se originan en ese régimen de zona franca. El cambio ya claramente se percibe a partir de 1998 (Gráfico 3). Este es también un período en que se instalan en el país grandes cadenas hoteleras transnacionales, las cuales progresivamente van dominando la parte más rentable del negocio turístico.

\section{Gráfico 3 \\ Costa Rica: participación de las exportaciones originadas en zona franca en el total de las exportaciones \\ Cifras en porcentajes}

$(1997-2010)$

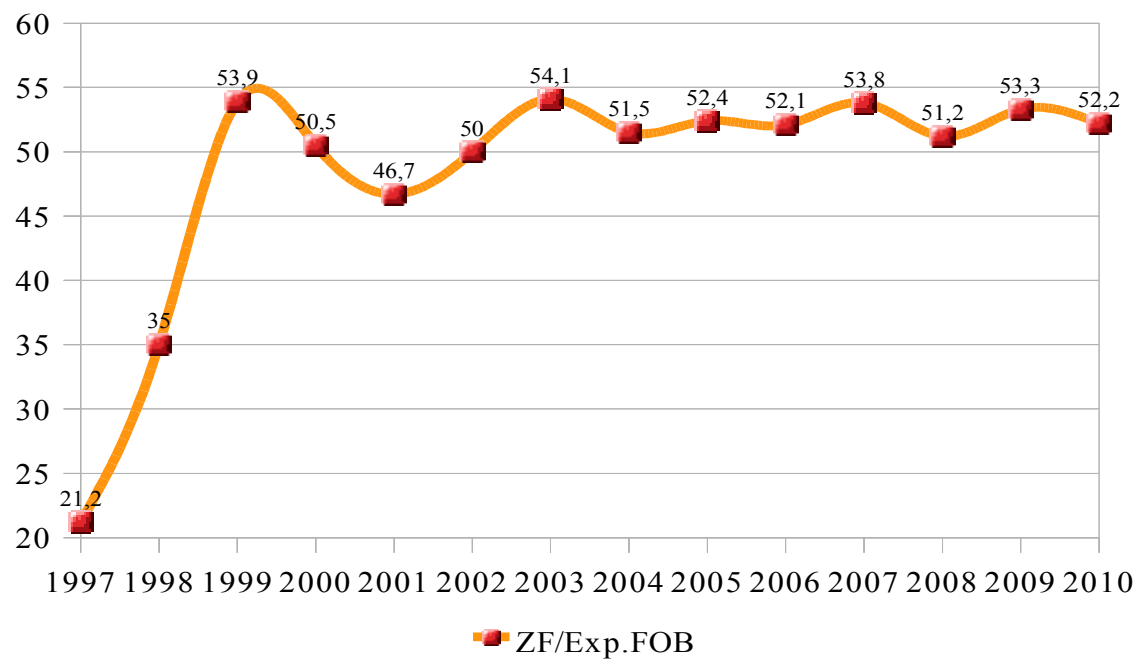

Fuente: Banco Central de Costa Rica

Una tercera fase inicia en 2005, cuando el incremento sustancial de los flujos de capital -en particular capitales de cartera de corto plazo e índole especulativa- introduce fuerzas que, tendencialmente, tienden a modificar algunos de los parámetros fundamentales en los que se asienta el modelo o estrategia neoliberal. Sobre eso se volverá posteriormente.

En correspondencia con lo anteriormente analizado, el patrón de ciclicidad de la economía costarricense tiende a responder a factores parcialmente diferentes en cada una de las tres fases o períodos.

Entre 1984 y 1997 las fases de retraimiento respondían principalmente a procesos de ajuste fiscal restrictivo que traían consigo elevación de las tasas de interés y la aplicación de políticas salariales muy conservadoras, lo que provocaba un desplome en el ritmo de crecimiento. No era infrecuente que, a la inversa, las fases expansivas fuesen empujadas principalmente por la laxitud fiscal, principalmente hacia el final de los sucesivos períodos gubernamentales. Esto dio lugar a una tesis que durante los años noventa devino muy popular entre economistas 
costarricenses, especialmente los de filiación ideológica neoliberal, así como en la prensa comercial local, usualmente muy favorecedora de las tesis de aquellos economistas: la tesis o hipótesis del "ciclo electoral". Con este concepto se hacía referencia a una presunta correlación entre los períodos electorales y la expansión excesiva del gasto público, lo cual llevaba implícita una especie de hipótesis psicológica en relación con el comportamiento de las dirigencias políticas en el sentido de que, a fin de favorecer al candidato oficialista y tratando además de concluir el período gubernamental gozando de una "buena imagen", el gobierno de turno se extralimitaba irresponsablemente en el manejo de las finanzas públicas. A su vez, esto obligaba a la nueva administración a la adopción de medidas fiscales restrictivas, ante las amenazas inflacionarias y de desestabilización económica que se acostumbra atribuir a las situaciones de desbalance fiscal negativo.

En general, esta hipótesis del ciclo electoral encuentra su fundamentación teórica en tesis asociadas a la teoría de la elección pública y, en particular, a los trabajos teóricos de Nordhaus (1975) y McRae (1977). Se basa, por lo tanto, en una hipótesis derivada a partir de las premisas propias del individualismo metodológico que, como se sabe, es la propuesta epistemológica 0 , si se prefiere, la hipótesis metodológica de base, en que se fundamenta la teoría económica neoclásica en sus múltiples expresiones y variantes. Sin pretender aquí profundizar en el asunto, conviene tener presente que el individualismo metodológico propone hipótesis de comportamiento individual racional y maximizador, formuladas desde supuestos que des-historizan a los sujetos y los vacía de todo contexto cultural. La psiquis de estos individuos racionales, carente de cualquier referente socializador, opera, de conformidad con una mecánica maximizadora, simple, lineal y determinista. Cada individuo, considerado aisladamente, toma decisiones racionales conducentes a la maximización de su personal función de utilidad, y luego, la suma o agregación de estas, da lugar a los resultados macroeconómicos. No se trata, en consecuencia, de una colectividad socialmente constituida a partir de la interrelación compleja entre personas y grupos de personas, sino tan solo una mera suma aritmética de comportamientos individuales, los cuales tienen lugar en un espacio abstracto, vacío de toda interrelación social. Siendo tales las bases en que se fundamenta la tesis del "ciclo electoral" se entiende que constituya una propuesta de interpretación sumamente frágil.

Dicho de otra forma, la presencia de picos en el déficit fiscal que tienden a coincidir con la fase final de los gobiernos, no encuentra más que una explicación superficial, sintomática -reducida con frecuencia a una mera correlación estadística- en esta tesis, justo porque los complejos factores políticos y económicos subyacentes a ese comportamiento, están siendo simplificados en exceso, cuando no abiertamente ignorados. En otros trabajos (Vargas, 2002, 2004), se ha discutido esa problemática en profundidad, en procura de demostrar que, en lo que a la realidad costarricense se refiere, la idea del ciclo electoral resulta insatisfactoria 
en cuanto desvía la atención hacia factores coyunturales superficialmente analizados-, mientras ignora los aspectos estructurales de fondo, insertos en el sistema tributario y en la forma como este se vincula (o se desvincula, según sea el caso) de la estructura productiva de la economía costarricense, todo lo cual es a su vez reflejo o manifestación fenomenológica de entramados de poder $-\mathrm{y}$, respectivamente, proyectos políticos y propuestas ideológicascomplejos, conflictivos y asimétricos. En lo esencial, la política de fomento exportador basculaba alrededor del estímulo fiscal, lo que implicó que, en la práctica, los sectores más dinámicos de la economía, vinculados a la exportación, el turismo y el negocio financiero privado, quedaran exentos de casi toda obligación tributaria. Correlativamente, el sostenimiento del sector público descansaba sobre la tributación proveniente de los sectores y actividades económicas vinculadas al mercado interno, usualmente menos dinámicas -que lo eran justamente por no tener prioridad en los esquemas vigentes de las políticas públicascomo, más en general, ese financiamiento provenía de la población asalariada de ingresos medios y bajos. Ha sido una fórmula regresiva e inequitativa que, de forma precisa, ha impreso al déficit fiscal el carácter estructural que le es característico, lo cual no impide que sea susceptible de oscilaciones episódicas generalmente agravadas por factores políticoelectorales. Estos últimos actuaban, entonces, como fuerzas que producían situaciones de agudización coyuntural, pero no eran, en modo alguno, los factores subyacentes determinantes del problema.

Un buen ejemplo de tales limitaciones en el análisis de la problemática fiscal por parte de la corriente económica neoliberal dominante, se encuentra en Camacho (2002) donde las diversas contribuciones y articulistas eluden discutir el problema estructural de largo plazo generado a partir de las políticas públicas que caracterizan a la estrategia neoliberal.

En resumen: entre mediados de los ochentas y hasta la segunda mitad de los noventas, se configura un patrón cíclico que tendía a estar dirigido por las fases de expansión y retracción del gasto público y del déficit fiscal. A su vez, el comportamiento de tales variables actuaba en forma espasmódica, bajo el impulso coyuntural de procesos electorales, pero sobre el telón de fondo de un problema estructural enraizado en la forma de vinculación/desvinculación entre el sistema tributario y la estructura productiva, el cual fue la concreción de intereses emergentes que, en el sistema institucional y de gestión de las políticas públicas, eventualmente devinieron hegemónicos (Vargas, 2005).

Desde 1998 en adelante, con la instalación en Costa Rica de la transnacional Intel, y la llegada posterior de otras grandes corporaciones transnacionales de alta tecnología, así como de cadenas hoteleras transnacionales que modifican el paisaje del negocio turístico, ese patrón se modifica en forma significativa, no porque el problema fiscal estructural -y sus ciclos espasmódicos de expansión y retraimientodesapareciera, sino porque un nuevo factor adquirió peso. Así pues, los 
ciclos de la economía pasan a estar afectados en mayor grado por el devenir de la economía mundial, según este se transmite vía exportaciones y turismo. Es, muy claramente, lo que acontece con el ciclo alto de 1998-1999 y, enseguida, la pronunciada baja del crecimiento que se registra en el trienio 2000-2002. Si bien este es un asunto que requiere más investigación, es del caso, sin embargo, que los datos disponibles acerca del comportamiento de las exportaciones, sugieren que las originadas en empresas transnacionales ubicadas en zona franca tienden a ser más sensibles a la coyuntura mundial, de lo que eran las exportaciones ligeras del período anterior a 1998.

Sin embargo, este patrón parece modificarse de nuevo a partir de 2005, ahora en mayor grado asociado al comportamiento de los flujos de capital que recibe el país. Entonces, el patrón cíclico tiende a responder principalmente a las entradas de capital, cuya influencia se vuelve determinante, por encima incluso del comportamiento de las exportaciones y de las cuentas fiscales.

Así, la afluencia de esos capitales registra una tendencia ascendente en el período posterior a 2004 (Gráficos 3 y 4), alcanzando una dinámica particularmente marcada en el trienio 2006-2008. Lo anterior a su vez se refleja en un incremento en las reservas monetarias en moneda extranjera, las cuales alcanzan durante estos años niveles históricos sin precedentes (Gráfico 5). Estas tendencias se interrumpen hacia 20082009, claramente en asocio con la situación de crisis económica mundial, pero retoma un camino ascendente en 2010 incluso ya desde finales de 2009.

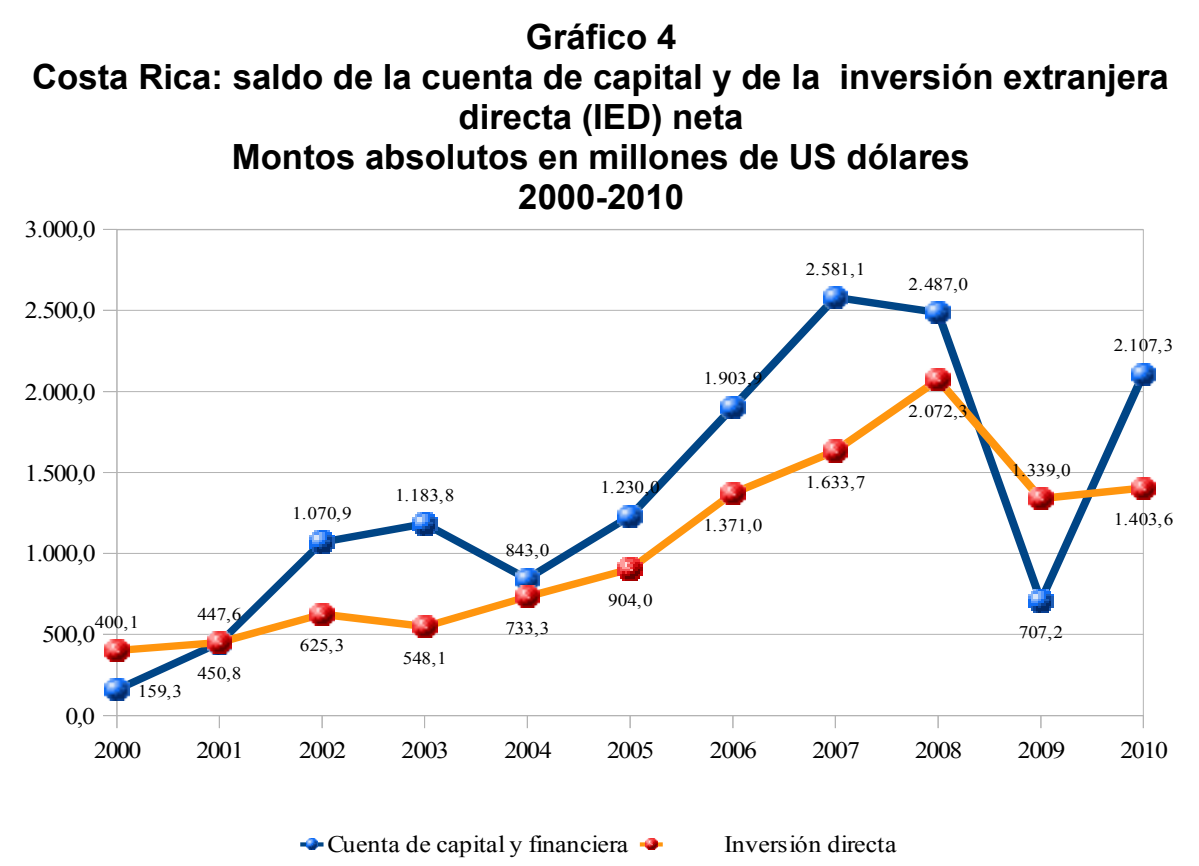

Fuente: Banco Central de Costa Rica 


\section{Gráfico 5}

Costa Rica: Cuenta de capital e inversión extranjera directa (IED) Porcentaje con respecto al PIB 2000-2010

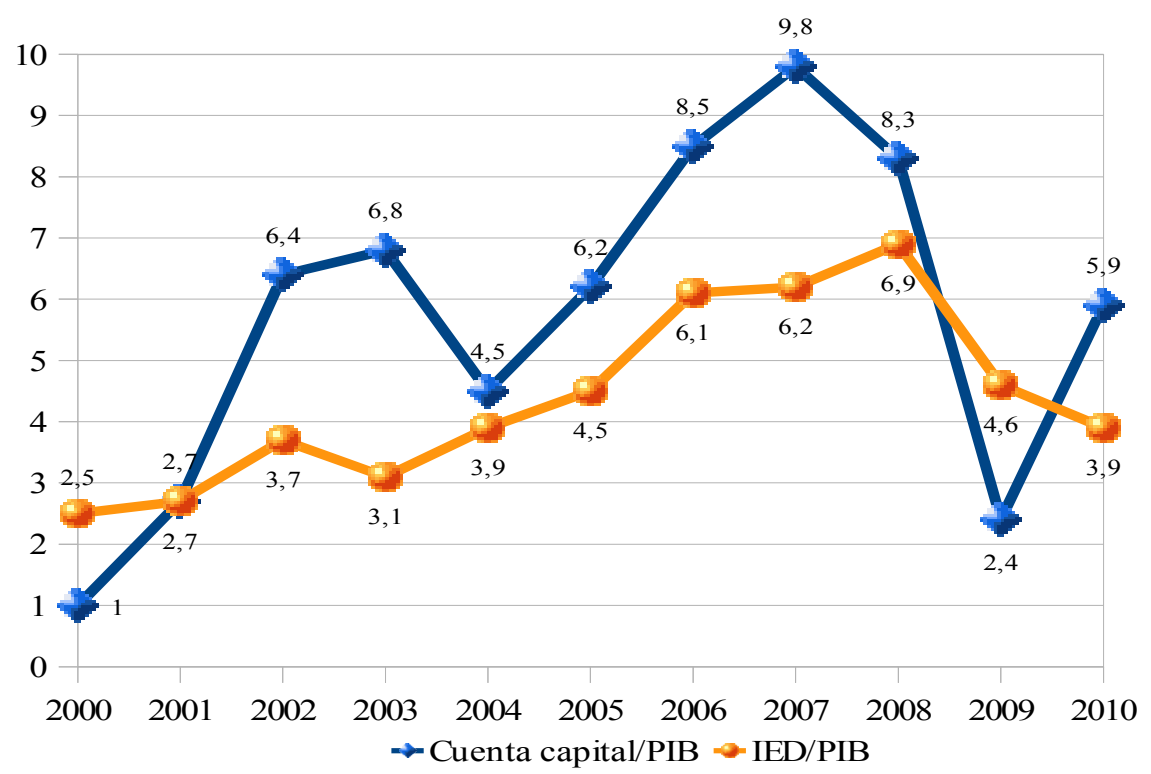

Fuente: elaboración propia con base en datos del Banco Central de Costa Rica

\section{Gráfico 6}

Costa Rica: Reservas monetarias internacionales en poder del Sistema Bancario Nacional (SBN) y del Banco Central de Costa Rica (BCCR) 2000-2010

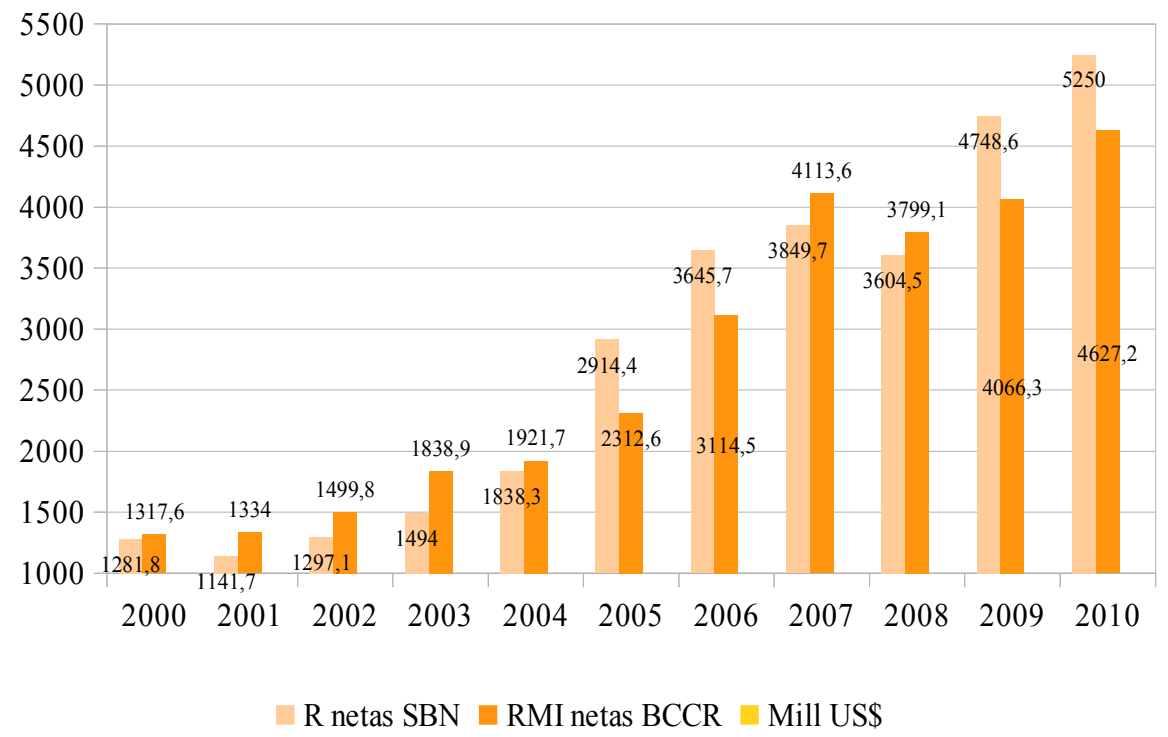

Fuente: Banco Central de Costa Rica 
Esta explosión en las entradas de capital es el factor que empuja al ciclo de elevado crecimiento de los años 2006-2007 (Vargas 2008c). Ello dio lugar a un recalentamiento económico que tiene su fase culminante durante el citado bienio, si bien ya en el segundo de esos años se percibe una leve tendencia declinante. Luego la fase de crisis, que empieza a impactar hacia 2008 y se profundiza en 2009, aparece asociada a una baja notable en las entradas de capital.

\section{El nuevo rol que asumen los capitales especulativos de corto plazo}

Hay en todo esto un detalle importante que conviene subrayar: a partir de 2005 (inclusive este año), y de forma más clara en los momentos de auge -2006 y 2007 con prolongaciones al 2008- se constata que los flujos totales de capital tienden a exceder ampliamente con respecto a las entradas de IED (Gráficos 3 y 4). En principio, se supone que esta última está orientada hacia la generación de capacidad productiva o, por lo menos, entraña un cambio en la propiedad de empresas o activos ya existentes. Es ciertamente un capital que goza de gran movilidad en virtud de las condiciones institucionales vigentes (libre movimiento de capitales) y gracias a las posibilidades que abren las tecnologías de la información y los transportes. No obstante lo anterior, y puesto que comporta una inversión en activos físicos productivos, adolece necesariamente de un grado de rigidez, ya que normalmente ninguna de estas empresas querrían abandonar el país sin al menos haber amortizado su inversión en capital fijo.

Esa amplia diferencia entre las entradas totales de capital respecto de la IED claramente sugiere que se han estado produciendo considerables entradas de capital de cartera, orientado a inversiones financieras de corto plazo. Estas inversiones, a diferencia de las productivas, tienen un carácter especulativo y trashumante. Según la evidencia histórica disponible, dichas inversiones tienden a provocar una agudización de la inestabilidad de las economías, la cual a menudo desemboca en crisis financieras y situaciones de aguda recesión y grave desempleo ${ }^{4}$.

Durán y Tenorio (2008), que conceptúan los capitales de cartera de forma similar a como se hace en este artículo, estiman que durante el período 2003-2007, los flujos de capital de cartera (especulativo) habrían alcanzado un total de US\$ 1806 millones, lo que representaría un 29,2\% del total de las entradas de capital registradas durante ese quinquenio (el resto correspondería a IED).

Considerando el período 2000 a 2010, se obtienen los datos que se presentan en el Cuadro 1.
4. Los distintos episodios de crisis financiera mundial así lo ratifican. La referencia podría prolongarse incluso a la crisis financiera de inicios de los setenta, que ponen fin al sistema monetario creado en 1944 en Bretton Woods (Sampson, 1983).

Pero los efectos de la deriva mundial de los capitales financieros se hace más clara hacia el decenio de los noventa, especialmente en su segunda mitad -las crisis en Asia, Rusia y Brasil, y luego, en el nuevo siglo, las de Argentina y Turquía (Stiglitz, 2002; ver también Soros, 1999)- hasta culminar en la crisis financiera mundial que empieza en Estados Unidos hacia agosto de 2007, y se degrada posteriormente como una crisis económica de alcances devastadores y proyección a mediano y largo plazo. 
5. El índice de tipo de cambio efectivo real con Estados Unidos alcanza un punto máximo en octubre de 2005 (valor de 111,0), mientras el índice de tipo de cambio efectivo real multilateral llega a un punto máximo en septiembre de ese mismo año (valor de 108,1). De ahí en adelante empieza un movimiento descendente tendencial, que se manifiesta de forma coincidente en ambos indicadores. Durante la fase aguda de la crisis, y empujados por la salida de capitales de corto plazo, ambos índices tuvieron una recuperación parcial que, en su punto más alto, los llevó a un valor de 87,9 en el caso del índice con Estados Unidos, y a 90,2 en el índice multilateral (ambos datos registrados en agosto de 2009). Se reinicia posteriormente el movimiento descendente, en coincidencia con la reactivación de los flujos de capital de cartera. Así a febrero de 2011 esos índices registran, respectivamente, los siguientes valores: $78,0 \mathrm{y}$ 79,3. Datos del Banco Central de Costa Rica.

\section{Cuadro 1}

Costa Rica: entradas de capital, IED e inversión de cartera Cifras en millones de dólares y porcentuales 2000-2010

\begin{tabular}{|c|c|c|c|c|c|c|c|c|}
\hline & \multicolumn{8}{|c|}{ Años } \\
\hline & $\begin{array}{l}2000- \\
2010\end{array}$ & $\begin{array}{l}2000- \\
2004\end{array}$ & $\begin{array}{l}2005- \\
2008\end{array}$ & 2006 & 2007 & 2008 & 2009 & 2010 \\
\hline $\begin{array}{l}\text { (1) Entradas } \\
\text { de capital }\end{array}$ & 14721,0 & 3704,6 & 8201,9 & 1903,9 & 2581,1 & 2487,0 & 707,2 & 2107,3 \\
\hline (2) IED & 11481,3 & 2757,6 & 5981,0 & 1371,0 & 1633,7 & 2072,3 & 1339,0 & 1403,6 \\
\hline $\begin{array}{l}\text { (3) Capital de } \\
\text { corto plazo }\end{array}$ & 3239,7 & 947,0 & 2220,9 & 532,9 & 947,4 & 414,7 & $-631,8$ & 703,7 \\
\hline$(2) /(1) \%$ & 78,0 & 74,4 & 72,9 & 72,0 & 63,3 & 83,3 & 189,3 & 66,6 \\
\hline (3) / (1) \% & 22,0 & 25,6 & 27,1 & 28,0 & 36,7 & 16,7 & $-89,3$ & 33,3 \\
\hline
\end{tabular}

Fuente: elaboración propia con base en datos el Banco Central de Costa Rica.

Las cifras del anterior cuadro dejan en claro de qué forma, en el período posterior a 2004, las fases de auge (2006-2007) o tan solo de relativa y vacilante recuperación de la economía costarricense y mundial (2010), tienden a estar acompañadas de un flujo incrementado de capitales especulativos y, en general, en un incremento en el total de las entradas de capital.

Así, el comportamiento de los flujos de capital se mueve a lo largo de una trayectoria de mediano plazo -quizá largo plazo-, la cual empieza en 2005, tiene una reversión momentánea en 2009 -obviamente relacionada con la situación de crisis mundial cuando la situación de pánico produce una fuga masiva de inversiones financieras hacia bonos del Tesoro estadounidense- pero retoma un camino ascendente en cuanto la economía mundial, como en lo particular la costarricense, dan signos (aunque contradictorios y vacilantes) de estabilización y recuperación. Los picos en el monto de las entradas de capital, en parte están asociados al aumento en la IED. Sin embargo es claro que hay un impacto relativamente más notable por parte de los flujos de capitales especulativos, los cuales son mucho más inestables: se expanden espectacularmente en coincidencia con los momentos de auge y se retraen de forma pronunciada en los de crisis o pánico. De tal forma, si el auge de 2006-2007 fue generosamente alimentado por la gran expansión que experimentan las entradas de capital de corto plazo, el frenazo que se registra en 2009 está principalmente influenciado por la salida masiva de ese tipo de capitales que la crisis económica y el pánico financiero suscitaron.

\section{Tendencia a la revalorización del colón frente al dólar}

Este comportamiento en las entradas de capital da lugar a un movimiento tendencial hacia la revaluación del colón frente al dólar, el cual, sobre la base de datos mensuales, empieza a registrarse desde finales de $2005^{5}$. Se inicia así, y con el tiempo se irá confirmando, una tendencia hacia la 
revaluación del colón frente al dólar, la cual se profundiza en los años de auge especulativo (2006-2007) y se prolonga al 2008, en un movimiento que aparece asociado a los masivos flujos de capitales de corto plazo que el país recibía en esos momentos. Como se ha visto, ese movimiento se revierte parcialmente en 2009 cuando la crisis y el ambiente de pánico financiero generalizado estimularon la búsqueda de "refugios" seguros, principalmente los bonos del Tesoro estadounidense. La relativa estabilización que tiene lugar hacia finales del 2009 y en el 2010 reactiva los flujos de capital de corto plazo y, con estos, el movimiento hacia la revaluación real del colón (Gráfico 7).

\section{Gráfico 7}

Costa Rica: Índices de tipo de cambio en términos reales con Estados Unidos y multilateral (2000-2010)

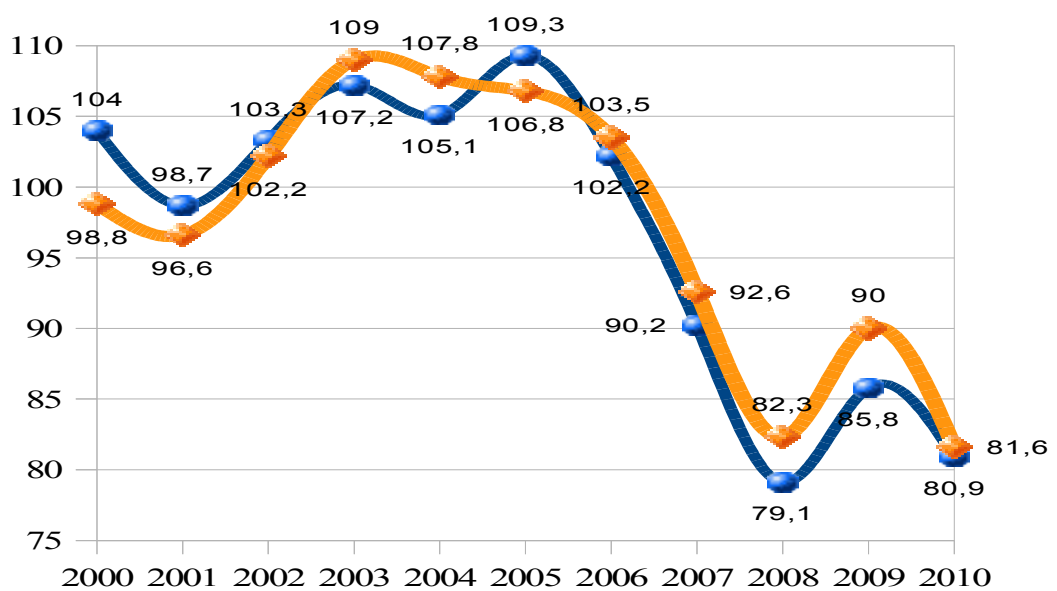

- Tipo real EEUU $\rightarrow$ Tipo real multilateral

Fuente: Banco Central de Costa Rica (Datos a diciembre de cada año)

Por otra parte, estos flujos de capital están relacionados con los desequilibrios de la cuenta corriente de la balanza de pagos en cuanto proveen el financiamiento que permite cubrir tales faltantes, al punto que, excediendo esos déficits, permite, como se ha visto, acumular reservas por montos muy considerables. A partir de 2005 y a lo largo del cuatrienio 2005-2008, los flujos netos registrados en la cuenta de capitales y financiera tienden a exceder ampliamente del déficit en la cuenta corriente, no obstante el movimiento ascendente que este también experimenta. Los efectos de la crisis revierten momentáneamente esta tendencia, la cual se restablece tan solo con que se den las primeras manifestaciones de relativa estabilización de las economías (Cuadro 2). 


\section{Cuadro 2}

Costa Rica: Balanza de pagos: cuenta corriente, de capitales e IED neta Cifras en millones de dólares (acumuladas para los períodos indicados) y porcentuales 2000-2010

\begin{tabular}{|l|c|c|c|c|}
\hline & $\mathbf{2 0 0 0 - 2 0 1 0}$ & $\mathbf{2 0 0 0 - 2 0 0 4}$ & $\mathbf{2 0 0 5 - 2 0 1 0}$ & $\mathbf{2 0 0 5 - 2 0 0 8}$ \\
\hline 1) Cuenta Corriente & $-12.134,0$ & $-3.822,0$ & $-8.312,0$ & $-6.437,3$ \\
\hline 2) Cta. Capitales-financiera & $14.721,0$ & $3.704,6$ & $11.016,4$ & $8.201,9$ \\
\hline 3) IED neta & $11.481,3$ & $2.757,6$ & $8.723,6$ & 5.981 \\
\hline 4) PIB dólares & $248.990,6$ & $85.307,7$ & $163.682,9$ & $98.652,6$ \\
\hline $1 / 4(\%)$ & $-4,9$ & $-4,5$ & $-5,1$ & $-6,5$ \\
\hline $2 / 4(\%)$ & 5,9 & 4,3 & 6,7 & 8,3 \\
\hline $3 / 4(\%)$ & 4,6 & 3,2 & 5,3 & 6,1 \\
\hline
\end{tabular}

Fuente: Elaboración propia con base en datos del Banco Central de Costa Rica.

\section{Conclusión: La estrategia neoliberal subvierte sus pilares fundamentales}

El período que se inicia en 2005 inaugura una nueva tendencia evolutiva dentro del modelo o estrategia desarrollista, la cual se visibiliza principalmente en las cuentas externas pero también tiene importantes repercusiones en el conjunto de la economía.

Esta tendencia general puede ser sintetizada en los siguientes movimientos más específicos:

- Los desequilibrios externos negativos, registrados en la cuenta corriente de la balanza de pagos, tienden a profundizarse.

- Los flujos de capital extranjero ganan en importancia.

- Dentro de esos movimientos de capital, la parte correspondiente a inversión extranjera directa (IED) evoluciona con notable dinamismo.

- Sin embargo, son principalmente los capitales de cartera, o capitales de corto plazo (de naturaleza especulativa), los que se expanden de forma más significativa, de modo que su peso relativo se incrementa de forma considerable.

Desde luego, y como es obvio, la tendencia se interrumpe en 2009 (ya empezaba a revertirse parcialmente desde 2008), pero es algo que acontece en asocio con una coyuntura extraordinaria: el impacto en Costa Rica de la fase aguda o de "caída libre" (Stiglitz, 2010). De hecho, son los capitales de corto plazo uno de los vehículos privilegiados a 
través de los cuales ese impacto se hace sentir, según se hace evidente en la salida neta de US \$631,8 millones de dólares en 2009 que se registra en los montos correspondientes a ese tipo de inversión.

Es ciertamente sintomático que con el restablecimiento de condiciones de relativa estabilización y certidumbre, una vez superada la fase aguda de la crisis (Stiglitz, 2010), tiende asimismo a restablecerse la entrada de capitales de corto plazo, en niveles que, al menos en términos absolutos, se comparan muy favorablemente con los que se registraban en los años anteriores a la crisis (como porcentaje del PIB en dólares su significación es ciertamente menor, pero ello también está afectado por la caída del dólar, lo que incrementa el valor en esa moneda de este último indicador). Es sin duda notable que esa inversión de cartera, cuyo desplome en 2009 fue mucho más agudo que el que registró la IED, manifieste en 2010 una recuperación mucho más marcada que esta última. Tal inestabilidad es, con toda probabilidad, indicio claro de su carácter especulativo y, por supuesto, ratifica su potencial desestabilizador. Además, todo esto resulta aún más notable si se recuerda que los años que precedieron a la crisis fueron de intenso auge especulativo y que, hasta inicios de 2011, la economía de Costa Rica -como en general las economías de los centros desarrollados, en particular Estados Unidos y Europa- esté aún lejos de haber alcanzado su plena recuperación ${ }^{6}$. El caso es que, en esas condiciones de frágil e incompleta recuperación, los flujos de capital extranjero -claramente empujados por la recuperación de las entradas de capitales de corto plazo- exceden cómodamente los desequilibrios negativos en la cuenta corriente de la balanza de pagos (Gráfico 8). Así pues, se observa de nuevo una situación de exceso en la disponibilidad de divisas. De ahí, a su vez, que el movimiento hacia la revalorización del colón frente al dólar se haya restablecido.

\section{Gráfico 8}

Costa Rica: saldos en las cuentas corriente y de capitales de la balanza de pagos. Cifras en millones de US dólares años 2000-2010

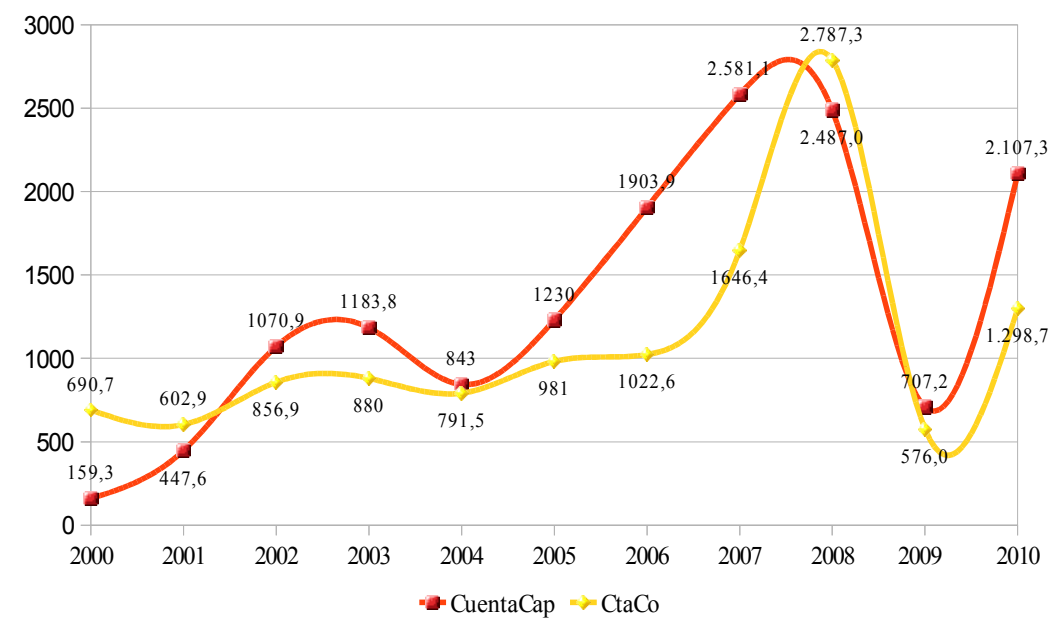

Fuente: elaboración propia con base en datos del Banco Central de Costa Rica ${ }^{7}$
6. Los datos del Índice Mensual de Actividad Económica (IMAE) del Banco Central muestran que durante los primeros meses de 2011, la economía de Costa Rica ha venido creciendo por debajo del $3 \%$ anual, dentro de una tendencia de debilitamiento del ritmo de la recuperación posterior a la recesión de 2009 . Esa tendencia empezó a manifestarse desde el segundo trimestre de 2010 y luego se fue agravando de forma progresiva.

\footnotetext{
7.Los datos del saldo en la cuenta corriente (Cta. Co. en el gráfico) son negativos, pero para efectos de facilitar la comparabilidad con los datos de la cuenta de capitales (Cuenta Cap. en el gráfico) son presentados en términos positivos.

Datos anuales acumulados a diciembre de cada año
} 
Esta revalorización real del colón frente al dólar introduce un severo disturbio en el modelo o estrategia neoliberal, en cuanto históricamente esta se construyó teniendo en las actividades orientadas hacia los mercados externos -exportaciones y turismo- su columna vertebral. En ese marco, la ideología dominante proponía hacer de la inversión extranjera un complemento y un refuerzo: ese capital venido de fuera presuntamente habría de contribuir en la consolidación de la infraestructura exportadora y turística.

La llegada de Intel hacia 1998 y, tras esta, la de otras corporaciones globales de alta tecnología así como de cadenas hoteleras transnacionales, introdujo una nueva etapa en el devenir de la estrategia neoliberal, con la cual se superó la fase que aquí ha sido designada como de exportaciones ligeras, en referencia a aquella primera etapa o fase en la evolución de la estrategia neoliberal que se despliega entre 1984 y 1997. El tejido productivo que se dio lugar durante esa primera etapa, en términos generales conserva vigencia, con una importancia relativa disminuida, sin duda, pero siendo, en todo caso, el que mantenía un ligamen efectivo entre actividades exportadoras y actividades de producción para el mercado interno. Hasta este punto, y en términos generales, se cumplió el ideologema que proponía una relación de complemento y refuerzo entre políticas de fomento exportador y turístico, y políticas de atracción de inversión extranjera.

A partir del 2005 esto se modifica en términos tales que esa relación se trastoca: pasa a ser una relación conflictiva y de contradicción. El caso es que el extraordinario aceleramiento en las entradas de capitales -tanto la parte correspondiente a IED, como especialmente la que proviene de inversiones de cartera de corto plazo- permite compensar con amplitud (por diferencias que, en promedio, se mueven en el rango de $1,6 \%$ a $1,8 \%$ respecto del PIB; Cuadro 2), los desequilibrios negativos en la cuenta corriente. Se instala así la tendencia hacia la revalorización del colón, la cual tiende a perpetuarse -con apenas una corrección parcial y momentánea- por un período que, al momento de escribir este artículo, ya excede de los cinco años y medio.

Téngase en cuenta las condiciones propias de la estrategia económica neoliberal, en cuanto esta ha implicado orientar una parte sustancial de la economía hacia los mercados externos vía exportaciones y turismo, de forma que la generación de empleos, como también el crecimiento económico, dependen crucialmente de la evolución de tales actividades. En ese contexto, el tipo de cambio colón-dólar deviene, como es obvio, una variable clave por su decisiva influencia sobre la capacidad competitiva de las actividades exportadoras y de turismo en los respectivos mercados mundiales. La tendencia hacia la revalorización del colón, especialmente cuando se afirma como tendencia de mediano y largo plazo, implica una subversión de hecho en uno de los pilares principales que sustenta la competitividad. Ello implicaría la ruptura en uno de los parámetros más importantes en que se sustenta la estrategia neoliberal. 
Se pone así en tensión el modelo de crecimiento neoliberal, basado en las exportaciones y el turismo y, en particular, amenaza con destruir el tejido de empresas pequeñas y medianas de capital nacional que constituye la parte de la estructura exportadora y turística, en mayor grado integrado a la economía y sociedad nacionales, y las cuales, por cierto, han sido instrumentalizadas como máscara ideológica que facilita la legitimación política de este modelo o estrategia. Pero, asimismo, es un proceso que seguramente compromete las actividades -de la agricultura, la agroindustria y la industria manufacturera- cuya producción se orienta hacia el mercado nacional y que compiten con importaciones. De alguna manera, lo que se ha venido configurando es el síndrome típico que en teoría económica recibe la designación de "mal holandés", el cual hace referencia a la situación de revalorización del florín holandés a finales de los setentas e inicios de los ochentas del siglo XX, ocasionado por el exceso en la entrada de divisas generado a partir del descubrimiento de yacimientos petroleros en el Mar del Norte. Si bien, es usual que el concepto aparezca asociado a un exceso de moneda extranjera generado a partir de la exportación de productos primarios, el problema subyacente es el mismo si esa abundancia de dólares está ocasionada -como en el caso de Costa Rica- por un exceso en las entradas de capitales de corto plazo. Las consecuencias económicas son las mismas; constituye una fuerza que debilita el crecimiento económico y la generación de empleos, lo cual resulta aún más preocupante en un caso como el de la Costa Rica actual, cuando apenas se emerge del impacto negativo de la Gran Recesión Mundial de 2008-2009 y en un contexto en el cual no solamente se observa una vacilante recuperación en Estados Unidos y Europa, sino donde, sobre todo, va quedando cada vez más claro que persisten graves problemas estructurales -en particular los del déficit fiscal y los altos niveles de endeudamiento público y privado- que comprometen el crecimiento económico a mediano y largo plazo en esos centros desarrollados.

Este período posterior a 2005 también se caracteriza, como tendencia general, por desequilibrios incrementados en la cuenta corriente de la balanza de pagos. Estos, sin embargo, se vuelven "sostenibles" en cuanto, como se ha visto, las entradas de capital registradas resultan sustancialmente más elevadas. Pero esta sostenibilidad está claramente marcada por el signo de la contradicción. En realidad, es algo que se apoya sobre tres pilares de dudosa solidez:

- El endeudamiento del sector privado, que probablemente ha sido alimentado, al menos en parte, con base en capitales externos ${ }^{8}$.

- La sistemática enajenación-extranjerización de activos nacionales que este proceso conlleva.

- El riesgo inherente al peso adquirido por los capitales de corto plazo, cuya inestabilidad ha quedado claramente demostrada.
8. A 2010, la posición de inversión internacional de Costa Rica registraba un saldo negativo de US $\$ 9,5$ miles de millones $(\$ 12,4$ miles de millones de activos; $\$ 21,9$ miles de millones de pasivos). Ello equivale a cerca de un $27 \%$ del valor del PIB en dólares. En 2000 el porcentaje respectivo era de algo menos del $21 \%$ y en 2005 de $18,5 \%$. Los datos anteriores son cálculos propios basados en datos del Banco Central de Costa Rica. 
9. El artículo 10.8 del Tratado de Libre Comercio con Estados Unidos, estipula total libertad -"y sin demora"- para las transferencias de todo tipo de capitales. Cfr. texto del capítulo 10 del Tratado en: http://www.comex.go.cr/acu erdos/cafta-dr/Texto\%20de $\% 20$ tratado/capitulo10.pdf
Aún si el Banco Central dispone de reservas suficientes para cubrir alrededor de 3,5 meses de importaciones (lo que se supone es relativamente aceptable), la persistencia a largo plazo de elevados desequilibrios en cuenta corriente de la balanza de pagos, puede resultar amenazante, sobre todo si se da en el contexto de una economía ralentizada que, por ello mismo, posiblemente no solo enfrentará problemas en las cuentas públicas (en buena medida originados en la falta de dinamismo económico), sino también situaciones de inestabilidad social y deslegitimización del sistema político, que el estancamiento económico tiende a agravar. Sin duda, pocas son las posibilidades de despegue de la economía, de forma que esta genere suficientes empleos y una mejora significativa en los ingresos, bajo condiciones de persistente y paulatinamente agravada sobrevalorización del colón.

De tal forma, la fase que se inaugura en 2005 plantea retos nuevos e inéditos a la estrategia neoliberal. El caso es que tienden a dominar tendencias que la subvierten, siendo especialmente paradójico el hecho de que esa subversión proviene de dentro mismo de la estrategia y se alimenta de su propia ideología, en cuanto es la premisa dogmática que proclama la inviolabilidad del libre flujo de capitales ${ }^{9}$, lo que ha promovido la emergencia de una situación contradictoria que amenaza debilitar seriamente la estructura productiva exportadora y turística. No puede descartarse que la persistencia de una situación tal implique la destrucción de cuanto menos los segmentos más vulnerables, que son seguramente los vinculados al capital nacional, especialmente las empresas pequeñas y medianas.

Las razones que explican la situación planteada son seguramente diversas y complejas. Atienden tanto a condiciones propias de la economía y la institucionalidad vigentes en Costa Rica -lo que le concede cierta ventaja en materia de atracción de capitales extranjeros, relativamente a países de su entorno cercano -como también a condiciones propias de la economía mundial- en particular el tipo de políticas aplicadas en los centros desarrollados ante la crisis económica mundial que empezó a finales de 2007, así como de las formas normativo-institucionales en que se fundamenta la globalización, y las tendencias que la caracterizan. Sin duda, subyace a todo esto juegos de poder $\mathrm{y}$, respectivamente, proyectos políticos e ideológicos sumamente complejos, asuntos que no serán abordados por razones de espacio en este artículo.

\section{Bibliografía}

Amín, S. (1999). El capitalismo en la era de la globalización. Madrid: Paidós Ibérica, S.A.

Amín, S. (2005). Más allá del capitalismo senil: por un siglo XXI no norteamericano. Buenos Aires: Paidós. 
Camacho, E. (editora) (2002). Costa Rica: una economía frente al desafío fiscal. San José: Academia de Centroamérica.

Chomsky, N. (1995). Democracia y mercados en el nuevo orden mundial. En: Chomsky, N. y Dieterich, H. La sociedad global. México: Joaquín Mortiz, S.A, pp. 15-47.

Durán, R. y Tenorio, E. (2008). Costa Rica: sensibilidad del capital de cartera al premio e implicaciones para la política económica (19912007). San José: Banco Central de Costa Rica.

Greenspan, A. (2008). La era de las turbulencias. Madrid: B, S.A.

Lizano, E. (1988). Desde el Banco Central. San José: Academia de Centroamérica.

Lizano, E. (1999). Ajuste y crecimiento en la economía de Costa Rica: 1982-1994. San José: Academia de Centroamérica.

Lizano, E. (2000). Política económica y desarrollo nacional. En: Jiménez, $\mathrm{R}$. Los retos políticos de la reforma económica en Costa Rica. San José: Academia Centroamericana, pp. 179-220.

Lizano, E. (2005). Veinte años sin crisis financieras (1984-2004): el caso de Costa Rica. En: López, G. y Herrera, R. Volatilidad y vulnerabilidad: el caso de Costa Rica, veinte años (1984-2004) sin crisis. San José: Academia de Centroamérica.

Lizano, E. (2010). Acerca del “¿qué?” y el “¿cómo?”. San José: Academia de Centroamérica.

Lizano, E. y Zúñiga, N. (1999). Evolución de la economía de Costa Rica durante el período1983-1998: ni tan bien, ni tan mal. San José: Academia de Centromérica.

López, J. R. (1986). Los orígenes económicos de la crisis en Centroamérica. En: Rivera, Sojo y López. Centroamérica: política económica y crisis. San José: DEI-ICADIS-UNA, pp. 115-201.

Loría, M. (2005). Vulnerabilidad y crisis en economías emergentes. En: López, G. y Herrera, R. Volatilidad y vulnerabilidad: el caso de Costa Rica, veinte años (1984-2004) sin crisis. San José: Academia de Centroamérica.

López, V. (1999). Asia en transición: auge, crisis y desafíos. México: Siglo $\mathrm{XXI}$. 
Mac Rae, D. (1977). A political model of the business cycle. Jornal of Political Economy, 85,239-63.

Nordhaus, W. (1975). The political business cycle. Review of Economic Studies, 42, 169-90.

Petras, J. y Veltmeyer, H. (2004). Las dos caras del imperialismo: vasallos y guerreros. México: Lumen S.A.

Plihon, D. (2003). El nuevo capitalismo. México: Siglo XXI.

Sachs, J. (2006). El fin de la pobreza. Cómo conseguirlo en nuestro tiempo. Buenos Aires: Sudamericana S.A.

Sampson, A. (1983). Los bancos y la crisis mundial. Madrid: Grijalbo S.A.

Sevares, J. (2005). El imperio de las finanzas sobre las economías, las empresas y los ciudadanos. Buenos Aires: Norma.

Shenkar, O. (2008). El siglo de China. La floreciente economía de China y su impacto en la economía global, en el equilibrio del poder y en los empleos. Bogotá: Norma.

Sojo, C. (1991). La utopía del Estado mínimo: influencia de la AID en Costa Rica en los años ochenta. San José: CRIES.

Sojo, C. (1992). La mano visible del mercado. San José: CRIES.

Soros, G. (1999). La crisis del capitalismo global. La sociedad abierta en peligro. Madrid: Plaza \& Janés.

Soros, G. (2008). El nuevo paradigma de los mercados financieros. Para entender la crisis económica actual. México: Santillana.

Stiglitz, J. (2002). El malestar en la globalización. Buenos Aires: Santillana.

Stiglitz, J. (2006). Cómo hacer que funcione la globalización. Madrid: Santillana.

Stiglitz, J. (2010). Caída libre. El libre mercado y el hundimiento de la economía mundial. México: Santillana.

Timossi, G. (1989). Centroamérica. Deuda externa y ajuste estructural: las transformaciones económicas de la crisis. San José: DEI.

Vargas, L.P. (2002). Costa Rica: 1985-1997: Liberalización y ajuste estructural o la autodestrucción del neoliberalismo. San José: Editorial UNED. 
Vargas, L.P. (2003). La estrategia de liberalización económica (período 1980-2000). San José: Editorial de la Universidad de Costa Rica.

Vargas, L.P. (2004). La economía En: Rodríguez, E. (editor). Costa Rica en el siglo XX (tomo II). San José: Editorial UNED.

Vargas, L.P. (2005). Globalización y políticas económicas: mecanismos de determinación y condicionamiento. El caso de Costa Rica: 19842000. Tesis de doctorado, San José: Universidad de Costa Rica.

Vargas, L.P. (2008a). El verdadero rostro de la globalización. La globalización sin alternativas (tomo I). San José: Editorial UNED.

Vargas, L.P. (2008b). El verdadero rostro de la globalización. Los amos de la globalización (tomo II). San José: Editorial UNED.

Vargas, L.P. (2008c). La economía costarricense en los inicios del siglo XXI. En: Santana, A. (compilador) Costa Rica en los inicios del siglo $X X I$. México: Centro de Investigaciones sobre América Latina y el Caribe.

Vargas, L.P. (2010). La llave y el candado: ideología y realidad de la propiedad intelectual. San José: Editorial UNED.

Vilas, C.M. (2003). Seis ideas falsas sobre la globalización. En: Fernández, J. (editor). Globalización: crítica a un paradigma. México: Universidad Nacional Autónoma de México, pp. 69-101.

Villamizar R. y Mondragón J.C. (1995). Zenshin: lecciones de los países del Asia-Pacífico en tecnología, productividad y competitividad. Bogotá: Norma.

Villarreal, R. (1984). La Contrarrevolución Monetarista: Teoría, Política Económica e Ideología del Neo-liberalismo. México: Océano. 